\title{
К вопросу о проблеме ответственности за фальсификацию сведений о развязывании Второй мировой войны В зарубежной историографии 1960-2000-х гг.
}

\author{
Н.В. Королькова \\ Белгородский государственный национальный исследовательский университет, \\ РФ, 308015, г. Белгород, ул. Победы, 85 \\ E-mail: nat.korolkova@list.ru
}

\begin{abstract}
Аннотация. Статья посвящена проблеме фальсификации исторических сведений о развязывании Второй мировой войны. Несмотря на огромное количество источников, документальной, исследовательской и мемуарной литературы о событиях Второй мировой войны, эта тема для учёных остается неисчерпаемой. Глобальный кризис мировой цивилизации в середине XX века еще долгий период времени будет трансформировать взгляды учёных-историков. Имеющиеся в настоящее время источники и документация в принципиальном плане достаточны для того, чтобы с позиции непредвзятого подхода дать исторически достоверную картину этих событий, но оценки этих событий до сих пор носят политически направленный характер, что отражается в историографии 2-й половины XX в. - начала XXI в.
\end{abstract}

Ключевые слова: Вторая мировая война, историография Второй мировой войны, фальсификация истории, Сталин, СССР, фашизм, Гитлер.

Для цитирования: Королькова Н.В. 2020. К вопросу о проблеме ответственности за фальсификацию сведений о развязывании Второй мировой войны в зарубежной историографии 1960-2000-х гг. Via in tempore. История. Политология, 47 (3): 532-540. DOI 10.18413/2687-0967-2020-47-3-532-540.

\section{On the issue of responsibility for falsifying information about the outbreak of the Second World War in the historiography of foreign countries in the 1960s-2000s}

\author{
Natalia V. Korolkova \\ Belgorod National Research University, \\ 85 Pobeda St., Belgorod, 308015, Russia \\ E-mail: nat.korolkova@list.ru
}

\begin{abstract}
The article deals with the problem of falsification of historical data on the outbreak of the Second World War. Despite the abundance of sources, documentaries, and memoirs on the events of World War II, this topic remains an endless one for scientists. The global crisis of world civilization in the middle of the twentieth century will long be transforming the views of historians. The sources and documentation currently available are, as a matter of principle, sufficient to provide an unbiased historical picture of these events, but the assessment of these events is still politically oriented. At the turn of the 20th-21st century, political forces emerged, both in Russia itself and near abroad, which grossly falsified history. One of the most topical topics examined in the article is the evaluation of international relations and diplomatic struggle on the eve of the Second World War. During the post-war period, many volumes of diplomatic documents, memoirs and diaries of statesmen, politicians, diplomats, numerous monographs and scientific articles were published. The chronicle of events that led to the bloodiest and most destructive war in world history has been restored day after day. You'd think the subject was thoroughly researched, but scientists keep coming back to it. This is entirely understandable, because it
\end{abstract}


involves responsibility for tens of millions of lives and broken human fates, for the incredible destruction and misery of many peoples.

Keywords: World War II, World War II historiography, falsification of history, Stalin, USSR, fascism, Hitler.

For citation: Korolkova N.V. 2020. On the issue of responsibility for falsifying information about the outbreak of the Second World War in the historiography of foreign countries in the 1960s-2000s. Via in tempore. History and political science, 47 (3): 532-540 (in Russian). DOI 10.18413/2687-0967-2020-47-3-532-540.

Минуло 75 лет со времени самого великого и знаменитого события в новейшей истории нашего государства - победы в Великой Отечественной войне 1941-1945 гг. К сожалению, всё меньше остается среди нас ветеранов-героев, которые могли бы рассказать нам и всему миру об истинной цене победы, о неоценимом подвиге советского народа, спасшего Родину и мир от фашизма. Эти реалии налагают дополнительную ответственность на учёных-историков, чей профессиональный и гражданский долг выражается в сотворении объективной истории Второй мировой войны, борьбе против попыток ее искажений и прямых фальсификаций.

Несмотря на огромное количество источников, документальной, исследовательской и мемуарной литературы о событиях Второй мировой войны, эта тема для учёных остается практически неисчерпаемой. Глобальный кризис мировой цивилизации в середине XX в. еще долгий период времени будет трансформировать взгляды историков. Имеющиеся в настоящее время источники и документация в принципиальном плане достаточны для того, чтобы с позиции непредвзятого подхода дать исторически достоверную картину этих событий, но оценка этих событий до сих пор носит политически направленный характер.

На рубеже XX-XIX веков некоторые политические силы как в самой России, так и ближнем зарубежье начали новый этап грубой фальсификации истории. К сожалению, современный социум поддается такому воздействию. Это связано с тем, что культурный уровень исторического мышления населения остается низким. На протяжении последних 100 лет наши соотечественники неоднократно испытывали и до сих пор переживают такие радикальные политические потрясения, что им зачастую трудно определиться с моральноэтическими и политическими ценностями.

В СМИ часто появляется много публикаций, выступлений, которые делают акцент не на осуждение фашизма, а на «цену победы». Чаще всего изучение истории Великой Отечественной войны сводится к роли Иосифа Сталина, штрафных батальонов и оценке его политической деятельности. Так, писатель Л. Млечин в радиоэфире «Эхо Москвы» заявил, что война советских людей с Германией была только «Отечественной» и не носила антифашистского характера [Федоров, 2015, с. 2].

Одной из самых актуальных тем, которые обсуждаются историками, является оценка международных отношений и дипломатическая борьба накануне Второй мировой войны. Периоду предвоенного времени в истории международных отношений посвящено немало публикаций. За послевоенное время были опубликованы многотомные серии дипломатических документов, мемуары и дневники государственных деятелей, политиков, дипломатов, огромное количество монографий и научных статей. Хроника событий, которые привели к самой кровопролитной и разрушительной войне в мировой истории, восстановлена день за днем. Казалось бы, эта тема досконально исследована, но учёные вновь и вновь возвращаются к ней. Это всецело объяснимо, так как речь идет об ответственности за десятки миллионов жизней и сломанных человеческих судеб, за невероятные разрушения и бедствия многих народов.

Однако существуют историки, учёные и политики на Западе, а также в некоторых государствах, образовавшихся на постсоветском пространстве, которые в своих книгах и 
публичных выступлениях пытаются исказить картину прошлого. Эти авторы стремятся навязать общественности мысль практически о «равной ответственности» Германии и Советского Союза за развязывание Второй мировой войны. Одновременно производятся попытки реабилитировать политику умиротворения фашистских агрессоров, которая проводилась правительствами западных стран в 30-е годы XX столетия.

В центре внимания зарубежных авторов находятся советско-германский пакт о ненападении от 23 августа 1939 г., а также советская внешняя и военная политика накануне Второй мировой войны. Современные отечественные историки совершенно обоснованно считают, что фальсификация истории советско-германского договора усилиями Евросоюза «возведена на межпарламентский, а по существу - на межгосударственный уровень». 3 июля 2009 г. на парламентской сессии ОБСЕ была принята резолюция, в которой Советский Союз рассматривается в качестве соучастника нацистской Германии. Таким образом, на Россию фактически возлагается ответственность за развязывание Второй мировой войны [Ржешевский и др., 2010, с. 256]. В этих условиях возрастает значение историографического анализа зарубежной научной литературы, которая посвящена предвоенным международным отношениям.

В период до 1991 г. советскими учеными был издан ряд коллективных монографий, которые были посвящены критике западной историографии Второй мировой войны: «Большая ложь о войне. Критика новейшей буржуазной историографии Второй мировой войны» [Коротков и др., 1971, с. 369]; «Критика основных концепций буржуазной историографии Второй мировой войны» [Жилин и др., 1983, с. 384]; «Правда и ложь о Второй мировой войне» [Кульков и др., 1988, с. 296]. Крупные исследования принадлежат авторству О.А. Ржешевского, Г.Н. Реутова, А.Н. Мерцалова и др. Данные исследования до сих пор являются актуальными, не потеряли своей важности.

После распада СССР начался новый этап в отечественной историографии. Множество российских историков провозглашали отказ от марксизма и фактически попали под влияние западной либеральной идеологии [Ржешевский и др., 2010, с. 20-21]. На социум обрушились лавины исторических публикаций, которые были рассчитаны на ажиотаж, не имея подтвержденных исторических фактов и документов. Но, невзирая на множество трудностей переходного периода, в отечественной исторической науке продолжают проводиться профессиональные исторические исследования [Минц, 2011, с. 75].

Многие зарубежные учёные и исследователи 2-й половины XX в. находились под сильным прессингом со стороны господствовавших внешнеполитических и идеологических доктрин, а потому в формировании зарубежной историографии истории международных отношений в канун начала Второй мировой войны выделяют два главных периода: 1 период (1945 - конец 1980-х гг.) чаще всего совпадает с течением Холодной войны; начало второго периода (с 1991 г.) в изучении Второй мировой войны было связано с окончанием Холодной войны, распадом СССР и крахом мировой системы социализма.

Множество историков в Великобритании изучали вопрос о начале Второй мировой войны. Самыми популярными считаются А.Дж.П. Тейлор и его книга «Истоки Второй мировой войны» [Tailor A.J.P., 1961], книга однофамильца предыдущего автора Телфорда Тейлора «Мюнхен. Цена Мира» [Tailor Т., 1977], известный исследователь Дональд Камерон Уатт и его труд «Слишком серьезное дело. Европейские вооруженные силы и подход ко Второй мировой войне» [Watt, 1975], Симон Ньюмен «Март 1939 года: британская гарантия Польше» [Newman, 1976], Роджер Паркинсон «Мир для наших времен. Мюнхен в Дюнкерк - история изнутри» [Parkinson, 1977], Энтони Адамсвайт «Франция и наступление Второй мировой войны» [Adamthwaite, 1977].

Историографии британского авторства присущ высокий интерес к роли политики умиротворения в развязывании Второй мировой войны. В изучении данного направления английской историографией выделяют два основных течения - консервативное и либеральное. Каждое из направлений в английской историографии, невзирая на существенные 
различия между ними, обнаруживает близкую связь с властвующей политикой того времени [Беляева, 1989, с. 201].

Начало критического подхода к оценке внешней политики Невилла Чемберлена связаны с ролью Уинстона Черчилля в реалиях того времени. В течение дебатов в парламенте Черчилль назвал мюнхенское соглашение «полным и абсолютным поражением» без войны, нарушившим равновесие на территории Европы, которое вело к завлечению Великобритании в зону воздействия фашистской Германии. Что интересно, в тот же период, У. Черчилль, вопреки себе самому, убеждал всех, что путь, избранный Н. Чемберленом, «требовал величайшего мужества» [Черчилль, 1991, с. 148-149]. В своих мемуарах Черчилль называл советско-германский пакт «одиозным и противоестественным актом» [Черчилль, 1991, с. 179]. Позже многие оценки, которые были высказаны У. Черчиллем, были повторены английскими учёными-историками.

В военные и начальные послевоенные годы в рамках либерального течения английской историографии обнаружилась антифашистская тенденция. Уильям и Зельда Коутс в 1945 г. выпустили фолиант «История англо-советских отношений». Авторы, которые симпатизировали СССР, проштудировали немалое число документов, в том числе опубликованных материалов парламентских дебатов и британской прессы. Главное достоинство издания - это освещение двусторонних связей между Советским Союзом и Великобританией на обширном фоне развития международных отношений в Европе и мире. Авторы полагали, что даже в 1939 г. можно было спасти мир, но правительство Н. Чемберлена представляло Советский Союз как «третьеразрядную державу» [Coates, 1945, p. 602-603]. Предоставление гарантий Польше без предварительных договорённостей с Советским Союзом авторы считали «сумасшествием», что впоследствии привело к неудаче англо-франко-советских переговоров [Coates, 1945, p. 605].

В Германии весьма известными источниками по историографии Второй мировой войны считаются представители консервативного направления Ганс-Адольф Якобсен «Национал-социалистическая внешняя политика 1933-1938 гг.» [Jakobsen, 1968], Клаус Гильдебранд и его книга «Внешняя политика Германии 1933-1945 гг. Расчет или догма?» [Hildebrand, 1980], а также Андреас Хильгрубер «Советская внешняя политика во Второй мировой войне» [Hillgruber, 1979]. Ученые опубликовали десятки изданий по истории Второй мировой войны. Мнение авторов исходит из утверждения о «равной вине» за развязывание Второй мировой войны. В особенности резкой критике со стороны западногерманских учёных и авторов подвергался советско-германский Пакт о ненападении.

Во время Холодной войны в германской историографии Второй мировой войны властвовало консервативное направление, избегавшее крайностей, свойственных неонацизму, но категорически придерживавшихся антисоветского направления [Мерцалов, 1978, с. 23-26]. По отношению к Советскому Союзу создавался образ врага.

Классическим примером этого является крайне предвзятое издание проф. Г. Дамса «История Второй мировой войны». Основания фашистской агрессии профессор сводит к абсолютно субъективному фактору. Дамс полагает, что Гитлер «один принял решение, мнение граждан страны не спросил». Мюнхенский сговор автор оправдывает мнением, что западные страны поверили обещаниям фюрера о том, что Судетская область будет его конечным территориальным требованием. Автор стремился переложить ответственность за развязку войны на антагонистов Германии, безапелляционно на СССР [Мерцалов, 1978, c. 103].

В 60-70-е гг. XX столетия в немецкой исторической науке возобладало либеральное направление [Мерцалов, 1978, с. 23-26]. Под действием разрядки международной напряженности принимался прокладывать себе путь наиболее объективный подход к оценке довоенных международных отношений. Тем не менее лидеры консервативного направления обладали сильным влиянием. Взгляды консерваторов продолжали определяться конфронтационными идеями, которые были характерны для периода Холодной войны. 
Ученые-историки либерального течения старались представить свои труды примером объективного подхода к событиям начала Второй мировой войны. Например, Б.Я. Вендт говорит в своей книге «Умиротворение, 1938. Экономический спад и Центральная Европа» о том, что он не собирается выступать в роли судьи, а его работа является «здравым, рассудительным и строго сравненным историческим исследованием» [Wendt, 1966, p. 140]. Но при этом автор полагает, что отказ Англии и Франции от противодействия немецко-фашистской экспансии в Восточной и Юго-Восточной Европе был определен тем, что Великобритания была сосредоточена на своей империи [Wendt, 1966, p. 39]. Следовательно, «прячется» основная цель политики умиротворения - устремить немецкую агрессию на Восток. В то же время, Вендт не упускает возможности упоминать об захватнических «аспирациях» Советского Союза касательно соседних стран [Wendt, 1966, p. 72-73].

Ещё одним научным событием стала книга германского историка И. Фляйшхауэра «Пакт. Гитлер, Сталин и инициатива германской дипломатии. 1938-1939». Фляйшхауэр определяет, что задачей его исследования является «предметный анализ источников» и осознанно оставляет за рамками своего исследования то, что, как он считает, относится к сфере догадок и домыслов [Фляйшхауэр, 1990, с. 72-73].

Немецкий учёный не поддерживает весьма популярного на Западе мнения о том, что в основе внешней политики Советского Союза перед Второй мировой войной стояли захватнические стремления. Автор указывает, что в чрезвычайной ситуации надвигавшейся войны старания советской дипломатии были направлены на обеспечение безопасности своего государства [Фляйшхауэр, 1990, с. 353-354]. Давая оценку последствиям заключения советско-германского пакта о ненападении, автор признает, что фюрер даже без «русского пакта» реализовал бы свои планы в отношении Польши. «Наравне с невероятным желанием завоеваний, - указывает Фляйшхауэр, - Гитлера подталкивал к этому экономический крах, в который он привёл Германию, и вытекающая отсюда нужда показать своим сторонникам весомые «успехи» [Фляйшхауэр, 1990, с. 342-343]. В то же время, как пишет Фляйшхауэр, согласие на такой договор было связано с «ошибками и преступлениями» [Фляйшхауэр, 1990, с. 358].

Анализ дипломатической борьбы вне общеисторического контекста нередко приводит И. Фляйшхауэра к односторонним выводам. Советско-германский пакт о не нападении, по мнению Фляйшхауэра, был прежде всего «актом умиротворения». Автор указывает, что «советское правительство по возможности пыталось избежать войны методами умиротворения» [Фляйшхауэр, 1990, с. 358]. Следовательно, внешняя политика СССР сравнивается с политикой умиротворения, проводившейся западными странами.

Необходимо подчеркнуть, что среди современных исследователей ФРГ есть много тех учёных, которые остались верны мнениям и мыслям, которые были характерны для периода Холодной войны. Следует отметить, к сожалению, что в последнее время обозначилась тенденция возврата германской историографии по ряду моментов на позиции 60-70-х годов XX столетия [Самсоненко, 2002, с. 104]. Таким образом, отечественным учёным-историкам необходимо более активно и аргументированно отстаивать свои научные позиции.

Решительную антироссийскую пропаганду носит литература по историографии Второй мировой войны, которая публикуется в Соединённых Штатах Америки. Бывший американский дипломат и посол в Москве Джордж Фрост Кеннан был одним из идеологов Холодной войны. В книге «Россия и Запад при Ленине и Сталине» автор заявлял, что политика СССР в 1933-1939 гг., по мнению западных держав, была «странной и загадочной» [Kennan, 1961, p. 293-294]. По его мнению, сталинская Россия никогда не была надежным партнером для Запада [Kennan, 1961, p. 312-313]. Обещания Советского правительства прийти на помощь Чехословакии в 1938 г. «стоили очень мало» в силу «географической реальности», поскольку СССР не имел общей границы с Германией. В то же время, он признает, что если бы Чехословакия решила сопротивляться Германии в 1938 г., она име- 
ла бы хороший шанс спастись [Kennan, 1961, p. 323-324]. Мюнхенский сговор Дж. Кеннан называет трагическим заблуждением и отчаянным актом умиротворения, совершенным Чемберленом и Даладье в тщетной надежде на то, что он удовлетворит амбиции Гитлера и сохранит мирное будущее Европы [Kennan, 1961, p. 322]. Дж. Кеннан пишет, что неудача англо-франко-советских переговоров в 1939 г. была вызвана тем, что Англия и Франция не были готовы пожертвовать независимостью Польши и прибалтийских государств в обмен на помощь Советского Союза [Kennan, 1961, p. 326-327]. Западные демократии, утверждает Дж. Кеннан, не могли ждать спасения с востока, а должны были рассчитывать только на самих себя [Kennan, 1961, p. 313]. Накануне Второй мировой войны их собственных сил для того, чтобы противостоять германской агрессии, было достаточно, но двумя годами позже - нет, поскольку перевооружение Германии шло очень быстро. В 1941 г. западным державам уже была необходима помощь СССР, за которую требовалось заплатить цену, «всю горечь которой вкусило наше поколение» [Kennan, 1961, p. 313]. В конечном счете такая политика западных держав, по словам Дж. Кеннана, привела к «трагическому цинизму» советско-германского пакта 1939 г. [Kennan, 1961, 295].

Вместе с тем Дж. Кеннан выносит на обсуждение несколько любопытных вопросов, которые требуют своего объяснения. Многие из них, конечно же, возникают в центре внимания огромного числа источников, которые посвящены личности Иосифа Сталина. Яркими эпитетами автор представляет для читателя образ Сталина, а именно его аномальную подозрительность, хитрость и отстранённость. Автор намеренно заставляет нас думать, что эти личностные качества Сталина будто намеренно нашли свое олицетворение в политических репрессиях, противостоянии немецким социал-демократам во время прихода фюрера к власти, заключении пакта о ненападении в 1939 г., а также в поступках советского лидера в военное и послевоенное время.

Естественно, когда роли Сталина уделяют слишком много внимания, при этом выставляя ее в качестве основного фактора, который бы определял внешнюю политику $\mathrm{CCCP,} \mathrm{и} \mathrm{оставляя} \mathrm{при} \mathrm{этом} \mathrm{все} \mathrm{остальные} \mathrm{более} \mathrm{значимые} \mathrm{факторы} \mathrm{где-то} \mathrm{позади,} \mathrm{то} \mathrm{дан-}$ ная постановка вопроса кажется весьма сомнительной, так как в существовавших реалиях внешней политике СССР была бы присуща высокая степень иррациональности.

Дж. Кеннан давал характеристику последним годам жизни советского лидера так: «прогрессирующее безумие и интеллектуальное увядание», при этом он отмечал неспособность Сталина адаптировать советскую внешнюю политику к запросам трансформирующейся действительности [Kennan, 1961, p. 101]. Уместно будет заметить, что, невзирая на личностные качества Сталина и особенности внутренней политики, которую он проводил, СССР все же дал понять, что может весьма неплохо приспособить свою внешнюю политику к модификациям, которые происходили в отношениях между мировыми державами.

Американские учёные в области истории Л. Фишер [Fisher, 1969], Д. Макшерри [McSherry, 1968], Д. Ротшильд [Rotschild, 1974], А. Улам [Ulam, 1968] сопоставляют советскую внешнюю политику с политикой имперской России. Популярный исследователь по истории России Л. Фишер в своей книге «Путь России от мира к войне: советские международные отношения, 1917-1941 гг.» заявляет, что СССР видел в нападении Германии на Польшу и Запад уникальную возможность возродить рубежи Российской империи и даже еще больше их расширить [Fisher, 1969, p. 349]. Д. Ротшильд утверждал, что «СССР и Германия представляли важнейшую угрозу межвоенному территориальному и социальному урегулированию» [Rotschild, 1974, p. 4]. Подобные мысли развивает А. Улам [Ulam, p. 1968].

Исследования американских историков, которые посвящены периоду предвоенного времени и характеристики международных отношений, наполнены обвинениями Советского Союза в экспансионизме и захватнической политике, вторжении во внутреннюю политику маленьких государств, а также стремлении к завладению их территорий. Следовательно, читателю внушается мысль об агрессивном курсе политики России, которая ей присуща генетически. В результате в корне американской историографии лежит весьма 
определенное желание дать оправдание внешней политике своего государства, которая, конечно же, нацелена на подавление желания со стороны России распространять своё влияние в Восточной Европе, на Ближнем и Среднем Востоке.

В завершение можно сделать вывод о том, что в условиях современных международных отношений и усиления в мире враждебно настроенной по отношению к России политики вновь активно используются оценки, которые господствовали в западной историографии в период Холодной войны. Отечественные же учёные в области исторических наук, опираясь на существующие документы, рассекреченные архивы, военную документацию, в своих исследованиях опровергают попытки фальсификаторов истории переложить ответственность за развязывание Второй мировой войны с ее бесчисленными жертвами и колоссальными разрушениями на СССР.

\section{Список литературы}

1. Беляева В.И. 1989. Британская историография мюнхенского сговора. Мюнхен: преддверие войны (Исторические очерки). М., Наука, 239.

2. Большая ложь о войне. Критика новейшей буржуазной историографии Второй мировой войны. 1971. М., Воениздат, 369.

3. Жилин П.А., Якушевский А.С., Кульков Е.Н. 1983. Критика основных концепций буржуазной историографии Второй мировой войны. М., Наука, 384.

4. Иванов А.Г. 2018. Дипломатическая борьба в Европе в канун Второй мировой войны. Краснодар, Кубанский гос. ун-т., 291.

5. Кульков Е.Н., Ржешевский О.А., Челышев И.А. 1988. Правда и ложь о Второй мировой войне. М., Воениздат, 296.

6. Ржешевский О.А. 1984. Война и история. Буржуазная историография США о второй мировой войне. Изд. 2. М., Мысль, 333.

7. Ржешевский О.А., Кульков Е.Н., Мягков М.Ю. 2010. Все о великой войне. М., Алгоритм, Эксмо, 256.

8. Самсоненко Г.Г. 2002. Отечественная и немецкая историография о роли СССР в победе над Германией в годы Второй мировой войны (1941-1945 гг.). Автореф. дис. канд. ист. наук. Санкт-Петербург, 21.

9. Минц М.М. 2011. Начало Великой Отечественной войны: Современная историография: Сборник обзоров и рефератов. М., ИНИОН РАН, Центр социал. науч.-информ. исслед. Отд. Истории, 160.

10. Федоров К.В. 2015. Ответственность за развязывание Второй мировой войны. Зарубежная историография. Гуманитарный журнал, вып. 7: 32-42.

11. Фляйшхауэр И. 1990. Пакт. Гитлер, Сталин и инициатива германской дипломатии. 1938-1939. М., Прогресс, 480.

12. Черчилль У. 1991. Вторая мировая война. В 3 книгах. Кн. 1. Т. І-II. Сокр. пер. с англ. М., Воениздат, 592 (in Russian).

13. Adamthwaite A. 1977. France and the coming of the Second World War. 1936-1939. London, Cass, 424.

14. Coates W.P. and Z.A. 1945. History of Anglo-Soviet Relations. London, Lawrence and Wishart, The Pilot Press, 816.

15. Fisher L. 1969. Russia's Road from Peace to War; Soviet Foreign Relations, 1917-1941. New York, Harpers and Row, 499.

16. Hildebrand K. 1980. Deutsche Außenpolitik 1933-1945. Kalkül oder Dogma? Stuttgart, Kohlhammer, 206.

17. Hillgruber A., Hildebrand K. 1990. Kalkul zwischen Macht und Ideologie. Der HitlerStalin Pakt: Parallelen bis heute. Zurich, Edition Interfrom, 80.

18. Hillgruber A. 1979. Sowjetische Außenpolitik im Zweiten Weltkrleg. Düsseldorf, Authenaum / Droste Taschenbücher Geschichte, 154.

19. Jakobsen H.-A. 1968. National-sozialistische Außenpolitik 1933-1938. Frankfurt am Mein, Berlin, West, 490. 
20. Kennan G. 1961. Russia and the West under Lenin and Stalin. Boston, Toronto, Atlantic monthly Press, 411.

21. McSherry J. 1968. Stalin, Hitler and Europe. Vol. 1. The Origins of the World War II. New York, The World Publ., 308.

22. Newman S. 1976. March 1939: the British guarantee to Poland. Oxford, Clarendon press, 253.

23. Parkinson R. 1971. Peace for our Times. Munich to Dunkirk - the inside story. London, Rupert Hart-Davis, 412.

24. Rotschild J. 1974. East Central Europe between the two World Wars. Seattle, London, Univ. of Washington press, 420 .

25. Taylor A.J.P. 1961. The Origins of the Second World War. London, Hamish Hamilton, 296.

26. Taylor T. 1979. Munich. The Price of Peace. New York, Random House, 1000.

27. Ulam A. 1968. Expansion and Coexistence: The History of Soviet Foreign Policy 1917-1967. New York, Washington, Praeger, 775.

28. Watt D. 1975. Too serious business. European armed forces and the approach to the Second World War. Berkley, Los Angeles, Univ. of California press, 200.

29. Wendt B.-J. 1966. Appeasement, 1938. Wirtschaftliche Rezession und Mitteleuropa. Hamburg, Europäische Verlagsanstalt, 162.

\section{References}

1. Belyaeva V.I. 1989. Britanskaya istoriografiya myunhenskogo sgovora. Myunhen. Preddverie voyny (Istoricheskie ocherki) [British Historiography of the Munich Conspiracy. Munich: The Eve of the War (Historical Essays)] M., Nauka, 239 (in Russian).

2. Bol'shaya lozh' o vojne. Kritika novejshej burzhuaznoj istoriografii Vtoroj mirovoj vojny. 1971 [Big lies about the war. Criticizing the latest bourgeois historiography of World War II]. M., Voenizdat, 369 (in Russian).

3. Zhilin P.A., Yakushevskij A.S., Kul'kov E.N. 1983. Kritika osnovnyh koncepcij burzhuaznoj istoriografii Vtoroj mirovoj vojny [Critique of the main concepts of bourgeois historiography of the Second World War]. M., Nauka, 384 (in Russian).

4. Ivanov A.G. 2018. Diplomaticheskaya bor'ba v Evrope v kanun Vtoroj mirovoj vojny [Europe's diplomatic struggle on the eve of World War II]. Krasnodar, Kubanskij gos. un-t., 291 (in Russian).

5. Kul'kov E.N., Rzheshevskij O.A., Chelyshev I.A. 1988. Pravda i lozh' o Vtoroj mirovoj vojne. [The truth and the lies about World War II]. M., Voenizdat, 296 (in Russian).

6. Rzheshevskij O.A. 1984. Vojna i istoriya. Burzhuaznaya istoriografiya SSHA o vtoroj mirovoj vojne [War and History. US bourgeois historiography of the Second World War]. Izd. 2-e, dop. i pererab. M., Mysl', 333 (in Russian).

7. Rzheshevskij O.A., Kul'kov E.N., Myagkov M.Yu. 2010. Vse o velikoj vojne [All about the great war]. M., Algoritm, Eksmo, 256 (in Russian).

8. Samsonenko G.G. 2002. Otechestvennaya i nemeckaya istoriografiya o roli SSSR v pobede nad Germaniej v gody Vtoroj mirovoj vojny (1941-1945 gg.) [German and Russian historiography on the role of the USSR in defeating Germany during the Second World War (1941-1945)]. Avtoref. dis. kand. ist. nauk. St. Petersburg, 21 (in Russian).

9. Minc M.M. 2011. Nachalo Velikoj Otechestvennoj vojny: Sovremennaya istoriografiya: Sb. obzorov i ref. RAN [The beginning of the Great Patriotic War: Modern historiography: Collection of reviews and abstracts]. M., INION RAN, Centr social. nauch.-inform. issled. Otd. Istorii, 160 (in Russian).

10. Fedorov K.V. 2015. Otvetstvennost' za razvyazyvanie Vtoroj mirovoj vojny [Responsibility for the outbreak of the Second World War. Foreign historiography]. Zarubezhnaya istoriografiya. Gumanitarnyj zhurnal, vyp. 7: 32-42 (in Russian).

11. Flyajshkhauer I. 1990. Pakt. Gitler, Stalin i iniciativa germanskoj diplomatii. 1938-1939 [Covenant. Hitler, Stalin and the German Diplomacy Initiative. 1938-1939]. M., Progress, 480 (in Russian).

12. Cherchill' U. 1991. Vtoraya mirovaya vojna. V 3 knigah [World War II. Three books.]. Kn. 1. T. I-II. Sokr. per. s angl. M., Voenizdat, 592.

13. Adamthwaite A. 1977. France and the coming of the Second World War. 1936-1939. London, Cass, 424.

14. Coates W.P. and Z.A. 1945. History of Anglo-Soviet Relations. London, Lawrence and Wishart, The Pilot Press, 816. 
15. Fisher L. 1969. Russia's Road from Peace to War; Soviet Foreign Relations, 1917-1941. New York, Harpers and Row, 499.

16. Hildebrand K. 1980. Deutsche Außenpolitik 1933-1945. Kalkül oder Dogma? Stuttgart, Kohlhammer, 206.

17. Hillgruber A., Hildebrand K. 1990. Kalkul zwischen Macht und Ideologie. Der HitlerStalin Pakt: Parallelen bis heute. Zurich, Edition Interfrom, 80.

18. Hillgruber A. 1979. Sowjetische Außenpolitik im Zweiten Weltkrleg. Düsseldorf, Authenaum / Droste Taschenbücher Geschichte, 154.

19. Jakobsen H.-A. 1968. National-sozialistische Außenpolitik 1933-1938. Frankfurt am Mein, Berlin, West, 490.

20. Kennan G. 1961. Russia and the West under Lenin and Stalin. Boston, Toronto, Atlantic monthly Press, 411.

21. McSherry J. 1968. Stalin, Hitler and Europe. Vol. 1 The Origins of the World War II. New York, The World Publ., 308.

22. Newman S. 1976. March 1939: the British guarantee to Poland. Oxford, Clarendon press, 253.

23. Parkinson R. 1971. Peace for our Times. Munich to Dunkirk - the inside story. London, Rupert Hart-Davis, 412.

24. Rotschild J. 1974. East Central Europe between the two World Wars. Seattle, London, Univ. of Washington press, 420.

25. Taylor A.J.P. 1961. The Origins of the Second World War. London, Hamish Hamilton, 296.

26. Taylor T. 1979. Munich. The Price of Peace. New York, Random House, 1000.

27. Ulam A. 1968. Expansion and Coexistence: The History of Soviet Foreign Policy 1917-1967. New York, Washington, Praeger, 775.

28. Watt D. 1975. Too serious business. European armed forces and the approach to the Second World War. Berkley, Los Angeles, Univ. of California press, 200.

29. Wendt B.-J. 1966. Appeasement, 1938. Wirtschaftliche Rezession und Mitteleuropa. Hamburg, Europäische Verlagsanstalt, 162.

\section{ИНФОРМАЦИЯ ОБ АВТОРЕ}

Королькова Наталья Валентиновна, аспирант кафедры всеобщей истории Белгородский государственный национальный исследовательский университет, г. Белгород, Россия

\section{INFORMATION ABOUT THE AUTHOR}

Natalia V. Korolkova, postgraduate student of the Department of General History Belgorod State National Research University, Belgorod, Russia 